\title{
Desire to Limit Childbearing and Its Associated Factors Among Married Women: Findings From A Cross-Sectional Survey In Karachi, Pakistan
}

Shama Razzaq ( $\nabla$ shama.razzak@gmail.com )

Aga Khan University

Saleem Jessani

Aga Khan University

Sumera Aziz Ali

Columbia University Mailman School of Public Health

Zahid Abbsai

Aga Khan University

Sarah Saleem

Aga Khan University

Research

Keywords: Fertility preference, Predictors, Squatter settlements

Posted Date: September 28th, 2020

DOl: https://doi.org/10.21203/rs.3.rs-78182/v1

License: (9) This work is licensed under a Creative Commons Attribution 4.0 International License.

Read Full License 


\section{Abstract}

Background:

Increasing population growth and uneven distribution of scarce resources is a hurdle for country's economic growth. Hence, we aim to determine desire to limit child bearing and factors associated with limiting child bearing among currently married women aged 15 to 49 years residing in squatter settlements of Karachi, Pakistan.

Methods:

A multistage cluster, cross sectional survey was conducted in randomly selected households of urban squatter settlements of Karachi. A total of 4,485 married, non-pregnant, were interviewed using a structured questionnaire and adapted Operational framework of "Pullum 1980" to determine potential factors associated with limiting family size. Outcome of interest was defined as a desire to limit childbearing among married women of reproductive age group. Multivariable regression was performed using SPSS version 13.0 .

Results:

The median age of participants was 30 years (IQR 25-35 years) and the median number of living children was 3 (IQR 2-4). Of 4485 women, 2109 (47\%) expressed desire to limit childbearing in future. Multivariable logistic regression showed that women of 18 to 27 years and 28 to 37 years (AOR $0.25,95 \%$ Cl: 0.19-0.39 and AOR 0.39, 95\% Cl: 0.22-0.47 respectively), illiterate (AOR 0.34, 95\% Cl: 0.21-0.53), and low wealth quintile (AOR $0.41,95 \% \mathrm{Cl}$ : $0.25-0.57$ ), not using any contraceptive method (AOR $0.53,95 \% \mathrm{Cl}$ : 0.44 to 0.63 ), sons less than daughters (AOR $0.74,95 \% \mathrm{Cl}: 0.62-0.87$ ), were less likely to limit childbearing. Women who practiced autonomy (AOR 1.25, 95\% Cl: 1.08-1.41) and perceived ideal family size as $\leq 2$ children (AOR 2.62,95\% Cl: 2.07-3.32) were more likely to limit childbearing.

Conclusion:

Age, education, low wealth quintile, having sons, autonomy and usage of contraceptives were determining factors of women's desire for limiting childbearing. Behavior modification strategies should be devised to modify fertility intentions among women to increase contraceptive use and fertility decline.

\section{Take Home Message:}

This community based study highlights fertility intention and basic associated factors and offers a ground to design approaches for modifying behavior towards less childbearing desire among women of reproductive age group in Pakistan where less desire to limit childbearing is reported.

\section{Plain English Summary:}


Unplanned population growth has major and serious implications on resources exploitation. In this community based survey, a group of married women were interviewed to determine their fertility intentions for future and sought women's desire to limit childbearing in future.

Women of reproductive age group from squatter settlement of Karachi were asked about whether they want more children or not in future and inquired about the factors which were associated with the intentions of limiting family size.

Of the 4485 participants, 2109 (47\%) showed the desire to limit family size in future. Various factors which were identified in this study associated with the less desire to limiting childbearing were young and relatively older age, no education, low wealth quintile, no use of contraceptives, and having less number of sons than daughters. Whilst, women with decision making capacity and having perceived ideal family size of two children were more intended to limiting of family size.

In conclusion; the study highlighted key independent factors to limiting childbearing for which behavior modification strategies should be devised to increase contraceptive use and fertility decline among women.

\section{Background:}

Pakistan is the 6th most populous country in the world. [1]. Approximately $35 \%$ of the Pakistan's population is under the age of 15 , and $4 \%$ is over the age of 60 , entailing a high dependency ratio [2]. Uncontrolled population growth and increasing size become a hurdle for country's economic growth once dividend is not balanced according to the available resources [3, 4]. High growing population raises demand for resources and, if inappropriately handled, has implications such as resources exploitation, poverty, high unemployment rates, population unrest, high crime rates, mental illnesses etc. $[5,6]$.

Fertility being fundamental component of population dynamics contributes in determining the rate of growing population [7]. Fertility preference provides direction towards the future fertility course to the magnitude one wants to acquire for preferred family size and indicator for general attitudes towards the use of family planning methods [8]. Whereas, in Pakistan, based on social, cultural and economic structure, society generally value for having high number of children and low demand for use of contraceptive methods resulting in high fertility [9]. The co-existence of high fertility, and high child mortality have been observed as demographic trend in developing countries, Pakistan still has a high neonatal and infant mortality rate [10].

Pakistan Demographic and Health Survey 2017-18, a nationally representative survey, shows that around $44 \%$ of women who are currently married want to limit childbearing or are permanently sterilized [7]. Generally, desire to limit childbearing depends on the number of existing children i.e. more living children a women has, greater the likelihood that women want no more children, since, survey showed that $89 \%$ of women with no children want to have a child sooner as compared to $14 \%$ of women who do not prefer more children [7]. In Pakistan, despite of policies, multiple programs and strategies, reported 
contraceptive prevalence is $35.4 \%$ which is substantially low, TFR reported in Pakistan is 3.6 births per women, whereas, in urban area TFR is 2.9 children/women which still represents favor towards a large family size [7]. A previous study conducted in Pakistan has shown that fertility preference is influenced by age of the woman, parity, child composition, education and household income determinants [9]. "Pullum 1980 " Framework suggests several factors influencing fertility intentions such as socio-economic status, socio-cultural norms, intra-spousal communication, and demographic factors. [8]. Thus, measuring fertility intentions and preferences along with its determinants, and ascertaining the degree to which they anticipate the fertility behavior, is important for population policy formulation and implementation of the programs designed for birth spacing [8]. Hence, the objective of this study was to determine fertility preferences and factors associated with limiting childbearing among currently married women in squatter settlements of Karachi, Pakistan.

\section{Methods:}

Study design and setting

A cross sectional survey was conducted on randomly selected households to interview married women of reproductive age group (MWRA) residing in 10 Sukh Stations, intervention sites, under Sukh initiatives. A tripartite partnership between Aman Foundation, Bill \& Melinda Gates Foundation, and the David \& Lucile Packard Foundation developed a family planning program called as Sukh initiative [11]. It has a vision to empower women for accessing contraceptive services by increasing knowledge, improving quality of services and expanding the basket of choices, contributing to the goals of Family Planning 2020. Thus, it aimed at increasing the use of modern contraceptives by 15 percentage points among married couples.

While involving multiple national and international partners including Aman Health Care Services, JHPIEGO Pakistan, dkt Pakistan, Aahung and Aman Telehealth (ATH), the project implemented a combination of approaches and strategies which included door-to-door community services by Aman Community Health Workers (CHWs) for counseling, referral and replenishment of supplies; life Skilled Based Education for the youth; tele-health services for providing family planning information and counseling; and enhancement of quality of family planning services among selected public and private facilities within the intervention sites. These sites were administrative units of Sukh initiatives' catchment population comprising of approximately 100,000 populations in each station. The sample of the survey was distributed among stations proportionate to their population size [11].

Sampling strategy and participant recruitment

The lists of households were available for all the Sukh stations through Aman Community Health Program (ACHP). For each station, the sequentially numbered blocks of 200-250 households were formed. The estimated sample size for each station was divided by 50 (the predefined number of women to be interviewed from each block) to achieve number of blocks to be included in the survey from each station. The number of blocks varied from a minimum of 33 in station 10 to a maximum of 76 in station 2. The households in each randomly selected block were then approached using systematic sampling 
technique, selecting every 5th house after selecting one house randomly. In a household where more than one eligible woman was found, one woman was selected randomly for the interview. A total of 4485 married and currently non-pregnant women in the reproductive age group 18 to 49 years were interviewed for this study.

Interviews

Interviews were conducted by trained field staff in the local language to ensure clear understanding of questions, appropriate response and relevant information from participants. Moreover, respondents were randomly selected from general population in order to minimize the selection bias. Chance of recall bias was minimal because women usually tend to recall and provide accurate information about previous pregnancy history, reproductive history and contraceptive usage. An operational framework of, "Pullum 1980 " was adapted and modified to determine factors associated with limiting family size. This framework focused on "Fertility Preferences" under which it has been asked about the "desire to limit child bearing". Considering this, it suggests several factors influencing fertility intentions such as socioeconomic status, socio-cultural norms, demographic factors, women's autonomy, contraceptive usage and history of previous pregnancy [8]. The fundamental questions included in this study were based on the aforementioned information on factors provided in the framework (Fig. 1).

Figure 1: Operational Framework to assess fertility preference

Outcome variable

To operationalize fertility preference; non-pregnant women were asked that if they would like to have a/another child, or would prefer not to have more children to determine 'Desire to limit childbearing'.

\section{Covariates}

'Educational level' was defined as those who never attended school or did not know how to read or write were considered as not educated while those who had been to school were categorized as educated. 'Wealth quintile' was defined as high, middle and low based on household possessions based on Principal Component Analysis scoring system (PCA). 'Women autonomy' was labeled as those having a say in choosing husband and deciding the date of marriage. 'Current contraceptive user' was defined as women using any contraceptive method currently. 'Media exposure' was defined as exposure to any media such as radio, television or newspaper providing information related to family planning methods. 'Living children composition' was categorized as having number of sons greater, equal to or less than number of daughter. 'Antenatal visits' were defined as frequency of antenatal visits during last pregnancy. 'Ever contraceptive user' was defined as women who have ever used any contraceptive method. 'Ever had poor pregnancies outcome' was defined as women if had any history of adverse obstetric outcome such as abortion, intrauterine death.

Sample Size 
The contraceptive use (any method) in urban Sindh, Pakistan was $42.7 \%$ as reported in Pakistan demographic health survey (PDHS) [12]. Further, assuming 2.5\% as bound on the error, $95 \%$ confidence level of significance and design effect of 2.247 reported in aforementioned PDHS survey [12], the minimum sample size estimated (using the Open Epi version 2.3) was approximately 3,375 currently married women in the reproductive age group. Considering the sensitivity attached with the family planning use and assuming a high refusal rate, sample size was inflated by $30 \%$ to adjust for nonresponders which turned out to be approximately 4385 after adjustment. However, final data collection was done from 4485 participants. The sample was distributed among stations proportionate to their population size.

Statistical methods:

Data were analyzed using SPSS 19.0. Descriptive analysis was done to calculate frequencies and proportions for categorical variables. Chi-square test was done to assess distribution of participants according to 'desire to limit childbearing', outcome status. The age of the participants was categorized keeping ten year interval which is widely used based on literature review for comparing young, middle and older aged women. The other continuous variables i.e. number of living children, age of the youngest child, ideal family size, antenatal visits and duration of marriages were also categorized based on commonly used categories in different literature and distribution of data in each category. To identify the factors associated with desire to limit childbearing, univariable analysis was carried out and crude odds ratios and their $95 \%$ confidence intervals along with $p$-values were calculated. Data were analyzed using logistic regression for both univariable and multivariable analysis. A p-value of less than 0.25 was considered as criterion for a variable to be significant in univariable analysis. Univariable analysis was followed by assessment of multi-collinearity between all independent variables. Cramer's $V$ and Phi was used to assess the collinearity between categorical independent variables, where cut off of $\geq 0.5$ was considered an inter-correlation between these variables. All independent variables with $p$-value $<0.25$ in the univariable analysis were selected for multivariable analysis by purposeful selection method. The significance of each independent variable in the multivariable analysis was assessed by its $p$-value and likelihood ratio testing. Statistical significance was defined as $p$-value less than 0.05 .

\section{Results:}

The median age of study participants was 30 years (IQR 25-35 years), while the median number of living children was 3 (IQR $2-4$ ). About $63 \%$ of the women had formal education while $37 \%$ women had never attended the school. Out of total married women, $47 \%(n=2109)$ expressed their desire to limit childbearing in future.

Table 1 describes distribution of participants according to factors which can influence desire to limit childbearing. More women with age $\geq 38$ years had higher desire to limit family bearing (50.5\%) as compared to younger age groups who wanted more children $(13.1 \%)(p$-value $<0.05)$. 
Table 1

Frequency distribution of factors associated with desire to limit child bearing among women $(n=4485)$,

Karachi, Pakistan

\begin{tabular}{|c|c|c|}
\hline \multirow[t]{2}{*}{ Characteristics } & $\begin{array}{l}\text { Want no more children } \\
\mathrm{N}(\%(95 \% \mathrm{Cl}))\end{array}$ & $\begin{array}{l}\text { Want more children } \\
\mathrm{n}(\%(95 \% \mathrm{Cl}))\end{array}$ \\
\hline & $2109(47 \%(43.9-50.1))$ & $2376(53 \%(49.9-56.1))$ \\
\hline \multicolumn{3}{|l|}{ Age * } \\
\hline 18 to 27 years & $153(7.3)$ & $866(36.4)$ \\
\hline 28 to 37 years & $892(42.3)$ & 1199 (50.5) \\
\hline 38 years and above & $1064(50.5)$ & $311(13.1)$ \\
\hline \multicolumn{3}{|l|}{ Education Status * a } \\
\hline Not educated & $812(34.2)$ & $882(41.9)$ \\
\hline Educated & $1564(65.8)$ & $1227(58.2)$ \\
\hline \multicolumn{3}{|l|}{ Ethnicity } \\
\hline Urdu & $719(34.1)$ & $715(30.1)$ \\
\hline Punjabi & $331(15.7)$ & $323(13.6)$ \\
\hline Sindhi & $264(12.5)$ & $365(15.4)$ \\
\hline Pushto & $270(12.8)$ & $309(13.0)$ \\
\hline Baluchi & $73(3.5)$ & $163(6.9)$ \\
\hline Others & $452(21.4)$ & $501(21.1)$ \\
\hline \multicolumn{3}{|c|}{ Ownership status of house } \\
\hline Owned & $1319(62.6)$ & $821(34.6)$ \\
\hline Rented & 789 (37.4) & $1555(65.4)$ \\
\hline \multicolumn{3}{|l|}{ Wealth quintile $* b$} \\
\hline High & $898(42.6)$ & 1015 (42.7) \\
\hline Middle & $410(19.4)$ & $440(18.5)$ \\
\hline Low & $801(38.0)$ & $921(38.8)$ \\
\hline \multicolumn{3}{|l|}{ Duration of marriage } \\
\hline$<5$ years & $88(4.2)$ & $812(34.2)$ \\
\hline 5 to 10 years & $468(22.2)$ & $965(40.5)$ \\
\hline
\end{tabular}




\begin{tabular}{|c|c|c|}
\hline \multirow[t]{3}{*}{ Characteristics } & Want no more children & Want more children \\
\hline & $\mathbf{N}(\%(95 \% \mathrm{Cl}))$ & n (\% (95\% Cl)) \\
\hline & $2109(47 \%(43.9-50.1))$ & $2376(53 \%(49.9-56.1))$ \\
\hline$>10$ years & $1553(73.6)$ & $599(25.2)$ \\
\hline \multicolumn{3}{|l|}{ Women autonomy * c } \\
\hline Yes & $1274(60.4)$ & $1178(49.6)$ \\
\hline No & $835(39.6)$ & $1198(50.4)$ \\
\hline \multicolumn{3}{|c|}{ Currently contraceptive user $* d$} \\
\hline Yes & $1189(56.4)$ & $829(34.9)$ \\
\hline No & $920(43.6)$ & $1547(65.1)$ \\
\hline \multicolumn{3}{|l|}{ Ideal Family Size * } \\
\hline$\leq 2$ children & $590(28.0)$ & $632(26.6)$ \\
\hline 3 to 4 children & $1203(57.0)$ & $1355(57.0)$ \\
\hline$\geq 5$ children & $916(15.0)$ & $389(16.4)$ \\
\hline \multicolumn{3}{|l|}{ Media Exposure * e } \\
\hline None & $1349(64.0)$ & $1574(66.2)$ \\
\hline Any media exposure & $760(36.0)$ & $802(33.8)$ \\
\hline \multicolumn{3}{|c|}{ Number of living children } \\
\hline No children & $25(1.2)$ & $289(12.2)$ \\
\hline 1 to 2 children & $288(13.7)$ & $1294(54.5)$ \\
\hline 3 to 4 children & $895(42.4)$ & $603(25.4)$ \\
\hline$\geq 5$ children & $901(42.7)$ & $190(8)$ \\
\hline \multicolumn{3}{|c|}{ Living children composition * $f$} \\
\hline Sons $>$ daughters & 905 (42.9) & $855(36.0)$ \\
\hline Sons $=$ Daughters & $474(22.5)$ & $386(16.2)$ \\
\hline Sons $<$ Daughters & $689(32.7)$ & $842(35.4)$ \\
\hline No Children & $41(1.9)$ & $293(12.3)$ \\
\hline Age of youngest child & & \\
\hline
\end{tabular}




\begin{tabular}{|c|c|c|}
\hline \multirow[t]{3}{*}{ Characteristics } & Want no more children & Want more children \\
\hline & $\mathbf{N}(\%(95 \% \mathrm{Cl}))$ & n (\% (95\% Cl)) \\
\hline & $2109(47 \%(43.9-50.1))$ & $2376(53 \%(49.9-56.1))$ \\
\hline Up to one year & $1821(86.3)$ & $1906(80.2)$ \\
\hline More than 1 year & $263(12.5)$ & $181(7.6)$ \\
\hline No children & $25(1.2)$ & $289(12.2)$ \\
\hline \multicolumn{3}{|l|}{ Antenatal visits * $\mathrm{g}$} \\
\hline$\leq 4$ visits & $1080(51.2)$ & $1220(51.3)$ \\
\hline 5 to 8 visits & $392(18.6)$ & $379(16.0)$ \\
\hline$>8$ visits & $637(30.2)$ & 777 (32.7) \\
\hline \multicolumn{3}{|c|}{ Ever contraceptive user $* \mathrm{~h}$} \\
\hline Yes & $1716(81.4)$ & $1424(59.9)$ \\
\hline No & $393(18.6)$ & $952(40.1)$ \\
\hline \multicolumn{3}{|c|}{ Ever had poor pregnancies outcome * $i$} \\
\hline Yes & $754(35.8)$ & $664(27.9)$ \\
\hline No & $1355(64.2)$ & $1712(72.1)$ \\
\hline \multicolumn{3}{|l|}{ *P-value $<0.05$} \\
\hline \multicolumn{3}{|c|}{$\begin{array}{l}\text { a Educational level was defined as those who never attended school or did not know how to read or } \\
\text { write were considered as not educated while those who had been to school were categorized as } \\
\text { educated }\end{array}$} \\
\hline \multicolumn{3}{|c|}{${ }^{\mathrm{b}}$ Wealth quintile was defined as high middle and low based on household possessions } \\
\hline \multicolumn{3}{|c|}{$\begin{array}{l}\text { c Women autonomy was defined as those having a say in choosing husband and deciding the date } 0 \\
\text { marriage }\end{array}$} \\
\hline \multicolumn{3}{|c|}{${ }^{d}$ Current contraceptive user was defined as women using any contraceptive method currently } \\
\hline \multicolumn{3}{|c|}{$\begin{array}{l}\text { e Media exposure was defined as exposure to any media such as radio, television or newspaper } \\
\text { providing information related to family planning methods }\end{array}$} \\
\hline \multicolumn{3}{|c|}{$\begin{array}{l}{ }^{f} \text { Living children composition was categorized as having number of sons greater, equal to or less thar } \\
\text { number of daughter }\end{array}$} \\
\hline \multicolumn{3}{|c|}{${ }^{g}$ Antenatal visits were defined as frequency of antenatal visits during last pregnancy } \\
\hline
\end{tabular}


Want no more children

$\mathrm{N}(\%(95 \% \mathrm{Cl}))$

$2109(47 \%(43.9-50.1))$
Want more children

$\mathrm{n}(\%(95 \% \mathrm{Cl}))$

$2376(53 \%(49.9-56.1))$

i Ever had poor pregnancies outcome was defined as women if had any history of adverse obstetric outcome such as abortion, intrauterine death

Similarly, more educated women $(65.8 \%)$ were inclined to limit child bearing as compared to illiterate ones $(58.2 \%)$ ( $p$-value $<0.05)$. Proportion of women practicing autonomy was high among women who desired to limit childbearing (60.4\%) as compared to those who wanted more children (49.6\%) ( $p$-value < 0.05). Similarly, a larger proportion of women who desired to limit family size were contraceptive users $(56.4 \%)$ as compared to those who wanted more children in future $(34.9 \%)$ ( $p$-value $<0.05)$. Likewise, proportion of women thinking ideal family size as $\leq 2$ children was high among those who desire to limit childbearing $(28.0 \%)$ as compared to their counterparts $(26.6 \%)$ ( $p$-value $<0.05)$. In addition, larger proportion of women who desire to limit childbearing had been exposed to media related to FP messages (36.0\%) and were currently using any contraceptive method (60.4\%) as opposed to those who wanted to have more children ( $p$-value $<0.05$ ). In contrast to this, smaller proportion of women who desired to limit childbearing had reported to have fewer sons than daughters $(32.7 \%)$ as compared to those who wanted to have more children $(35.4 \%)$ ( $p$-value $<0.05)$.

In Univariable logistic regression analysis, women less likely to have a desire to limit childbearing were relatively younger in the age categories of 15 to 24 years and 25 to 34 years (OR $0.46,95 \% \mathrm{Cl}: 0.23$ to 0.51 and OR $0.66,95 \% \mathrm{Cl}: 0.35$ to 0.78 respectively). In addition, uneducated women (OR $0.42,95 \% \mathrm{Cl}$ : 0.29 to 0.61 ), belonging to Baluchi ethnicity (OR $0.54,95 \% \mathrm{Cl}: 0.37$ to 0.81 ), to low wealth quintile (OR $0.44,95 \% \mathrm{Cl}: 0.29$ to 0.61 ), not current users of contraceptive methods (OR $0.61,95 \% \mathrm{Cl}: 0.47$ to 0.71 ), who have less number of sons than daughters (OR $0.84,95 \% \mathrm{Cl}: 0.67$ to 0.91 ), who have ever used family planning method (OR $0.56,95 \% \mathrm{Cl}: 0.46$ to 0.69$)$ were less likely to limit childbearing in future.

Women who showed desire to limit family size were those who practiced autonomy (OR 1.37, 95\% Cl: 1.12 to 1.56 ), who perceived ideal family size as $\leq 2$ children (OR $2.82,95 \% \mathrm{Cl}: 2.17$ to 3.31 ) and who had equal number of sons and daughter (OR $1.41,95 \% \mathrm{Cl} 1.17$ to 1.52 ) (Table 2). 
Table 2

Univariable analysis for factors associated with desire to limit child bearing among women, Karachi, Pakistan $(n=4485)$

\begin{tabular}{lll} 
Characteristics & Unadjusted OR $(95 \% \mathrm{Cl})$ & P value \\
\hline Age & $0.45(0.23-0.51)$ & $<0.001$ \\
18 to 27 years & $0.66(0.35-0.78)$ & \\
\hline 28 to 37 years & 1 & $<0.001$ \\
\hline 38 years and above & & \\
\hline Education status ${ }^{\text {a }}$ & $0.42(0.29-0.61)$ & \\
\hline Not educated & 1 & 0.24 \\
\hline Educated & & 0.17 \\
\hline Ethnicity & 1 & 0.26 \\
\hline Urdu & $0.86(0.67-1.11)$ & 0.003 \\
\hline Punjabi & $0.83(0.63-1.82)$ & 0.012
\end{tabular}

Ownership status

Owned

Rented

Wealth quintile ${ }^{b}$

High

Middle

Low

\section{Duration of marriage}

$<5$ years

5 to 10 years

$>10$ years

Women's autonomy ${ }^{c}$
1

$0.51(0.31-1.21)$

0.51
$0.53(0.3-1.11) \quad 0.25$

$0.44(0.29-0.61)$

0.003
$0.49(0.31-1.1) \quad 0.057$

$0.33(0.25-1.46)$

0.13 


\begin{tabular}{|c|c|c|}
\hline Characteristics & Unadjusted OR (95\% Cl) & $P$ value \\
\hline Yes & $1.37(1.12-1.56)$ & \multirow[t]{2}{*}{$<0.001$} \\
\hline No & 1 & \\
\hline \multicolumn{2}{|l|}{ Current contraceptive user ${ }^{d}$} & \multirow[t]{3}{*}{$<0.001$} \\
\hline Yes & 1 & \\
\hline No & $0.61(0.47-0.71)$ & \\
\hline \multicolumn{3}{|l|}{ Ideal family size } \\
\hline$\leq 2$ children & $2.82(2.17-3.31)$ & $<0.001$ \\
\hline 3 to 4 children & $1.56(1.31-1.82)$ & 0.003 \\
\hline$\geq 5$ children & 1 & \\
\hline Media exposure ${ }^{e}$ & & \multirow[t]{2}{*}{0.26} \\
\hline None & $0.71(0.32-1.10)$ & \\
\hline Any media exposure & 1 & \\
\hline \multicolumn{3}{|l|}{ Living children composition ${ }^{f}$} \\
\hline Sons $>$ daughters & 1 & \multirow[t]{4}{*}{$<0.001$} \\
\hline Sons = Daughters & $1.41(1.17-1.52)$ & \\
\hline Sons $<$ Daughters & $0.84(0.67-0.91)$ & \\
\hline No Children & $0.67(0.51-0.79)$ & \\
\hline \multicolumn{3}{|l|}{ Antenatal Visits ${ }^{g}$} \\
\hline$\leq 4$ visits & $0.90(0.79-1.12)$ & 0.42 \\
\hline 5 to 8 visits & $1.12(0.91-1.34)$ & 0.23 \\
\hline$>8$ visits & 1 & \\
\hline Ever contraceptive user ${ }^{h}$ & & \multirow[t]{3}{*}{$<0.005$} \\
\hline Yes & $0.56(0.46-0.69)$ & \\
\hline No & 1 & \\
\hline \multicolumn{2}{|l|}{ Ever had poor pregnancies outcome ${ }^{i}$} & \multirow[t]{3}{*}{0.12} \\
\hline Yes & 1 & \\
\hline No & $0.54(0.21-1.11)$ & \\
\hline
\end{tabular}


*P-value $<0.05$

a Educational level was defined as those who never attended school or did not know how to read or write were considered as not educated while those who had been to school were categorized as educated

${ }^{b}$ Wealth quintile was defined as high middle and low based on household possessions

${ }^{c}$ Women autonomy was defined as those having a say in choosing husband and deciding the date of marriage

${ }^{d}$ Current contraceptive user was defined as women using any contraceptive method currently

e Media exposure was defined as exposure to any media such as radio, television or newspaper providing information related to family planning methods

${ }^{f}$ Living children composition was categorized as having number of sons greater, equal to or less than number of daughter

${ }^{g}$ Antenatal visits were defined as frequency of antenatal visits during last pregnancy

${ }^{h}$ Ever contraceptive user was defined as women who have ever used any contraceptive method

${ }^{i}$ Ever had poor pregnancies outcome was defined as women if had any history of adverse obstetric outcome such as abortion, intrauterine death

On multivariable logistic analysis, almost all the factors in the univariable analysis retained their significance. Women less likely to have a desire to limit childbearing were younger 15 to 24 years and 25 to 34 years of age (AOR $0.25,95 \% \mathrm{Cl}: 0.0 .19$ to 0.39 ) and (AOR $0.39,95 \% \mathrm{Cl}: 0.22$ to 0.47 ) respectively, uneducated (AOR $0.34,95 \% \mathrm{Cl}: 0.21$ to 0.53 ), poor (AOR $0.41,95 \% \mathrm{Cl}: 0.25$ to 0.57 ), and not using any contraceptive method at the time of interview (AOR $0.53,95 \% \mathrm{Cl}: 0.44$ to 0.63 ). These women had less number of sons as compared to daughters (AOR $0.74,95 \% \mathrm{Cl}: 0.62$ to 0.87 ), and had ever-used a contraceptive method (AOR $0.49,95 \% \mathrm{Cl}: 0.35$ to 0.61 ).

Women who practiced autonomy (AOR $1.25,95 \% \mathrm{Cl}$ : 1.08 to 1.41 ), who perceived ideal family size as $\leq 2$ children (AOR 2.62, 95\% Cl: 2.07 to 3.32), and who have equal number of sons and daughters (AOR 1.13, $95 \% \mathrm{Cl}: 1.09$ to 1.38 ) were more likely to have a desire for limiting births (Table 3 ). 
Table 3

Multivariable analysis for factors associated with desire to limit child bearing among women, Karachi, Pakistan $(n=4485)$

\begin{tabular}{|c|c|c|}
\hline Characteristics & adjusted OR (95\% Cl) & $P$ value \\
\hline \multicolumn{3}{|l|}{ Age of respondents } \\
\hline 18 to 27 years & $0.25(0.19-0.33)$ & $<0.001$ \\
\hline 28 to 37 years & $0.39(0.22-0.47)$ & \\
\hline 38 years and above & 1 & \\
\hline Education status ${ }^{a}$ & & 0.002 \\
\hline Not educated & $0.34(0.21-0.53)$ & \\
\hline Educated & 1 & \\
\hline \multicolumn{3}{|l|}{ Wealth quintile ${ }^{b}$} \\
\hline High & 1 & \\
\hline Middle & $1.01(0.8-1.42)$ & 0.42 \\
\hline Low & $0.41(0.25-0.57)$ & 0.004 \\
\hline Women's autonomy ${ }^{c}$ & & 0.003 \\
\hline Yes & $1.25(1.08-1.41)$ & \\
\hline No & 1 & \\
\hline Current contraceptive user ${ }^{d}$ & & $<0.001$ \\
\hline Yes & 1 & \\
\hline No & $0.53(0.44-0.63)$ & \\
\hline Ideal family size & & $<0.001$ \\
\hline$\leq 2$ children & $2.62(2.07-3.32)$ & \\
\hline 3 to 4 children & $1.45(1.19-1.78)$ & \\
\hline$\geq 5$ children & 1 & \\
\hline Living children composition e & & $<0.001$ \\
\hline Sons $>$ daughters & 1 & \\
\hline Sons = Daughters & $1.13(1.09-1.38)$ & \\
\hline Sons $<$ Daughters & $0.74(0.62-0.87)$ & \\
\hline
\end{tabular}




\begin{tabular}{|c|c|c|}
\hline Characteristics & adjusted OR (95\% Cl) & $P$ value \\
\hline No Children & $0.53(0.35-0.81)$ & \\
\hline \multicolumn{3}{|c|}{ Ever used any contraceptive method ${ }^{f}$} \\
\hline Yes & 1 & \multirow[t]{2}{*}{$<0.001$} \\
\hline No & $0.49(0.35-0.61)$ & \\
\hline \multicolumn{3}{|l|}{ *P-value $<0.05$} \\
\hline \multicolumn{3}{|c|}{$\begin{array}{l}\text { a Educational level was defined as those who never attended school or did not know how to read or } \\
\text { write were considered as not educated while those who had been to school were categorized as } \\
\text { educated }\end{array}$} \\
\hline \multicolumn{3}{|c|}{ b Wealth quintile was defined as high middle and low based on household possessions } \\
\hline \multicolumn{3}{|c|}{$\begin{array}{l}{ }^{c} \text { Women autonomy was defined as those having a say in choosing husband and deciding the date of } \\
\text { marriage }\end{array}$} \\
\hline \multicolumn{3}{|c|}{ d Current contraceptive user was defined as women using any contraceptive method currently } \\
\hline \multicolumn{3}{|c|}{$\begin{array}{l}\text { e Living children composition was categorized as having number of sons greater, equal to or less thar } \\
\text { number of daughter }\end{array}$} \\
\hline${ }^{f}$ Ever contracep & ve ever used any cont & ethod \\
\hline
\end{tabular}

\section{Discussion:}

In our study sample every other woman expressed her desire to limit childbearing in future. Women who took their own decisions, consider ideal family size as two children, and had equal number of sons and daughter showed desire to limit family size. On the other hand, women who were younger, uneducated, poor, had less number of sons than daughters, and had never used a contraceptive method showed no desire to limit their family size.

Our study findings are consistent with a nationally representative survey, Pakistan Demographic and Health Survey 2017-18, which reported that approximately $44 \%$ of women who were currently married wanted to limit childbearing [7]. Whereas, comparison with a regional study conducted in Ethiopia, a nationally represented survey, showed that almost half i.e. $43 \%$ of currently married women wanted to have no more children.[13]. The desire for more children or intentions to limit childbearing depended on number of children women already had [13]. In our study, $42.4 \%$ of women with 3 to 4 children showed a desire to limit childbearing in future.

Association of age with fertility desire has shown conflicting results; evidence showed the women at both extremes of age can express desire for more children. For example one study in Kenya found that women of $\geq 24$ year of age were less likely to limit childbearing [8]. Furthermore, results from demographic health 
survey conducted in Bangladesh showed that women at late childbearing stage had more children [14]. Whereas, Demographic and health survey of Nigeria revealed that women 15 to 24 years of age reported using modern contraceptive methods thus reflecting their sensitization for high fertility implications and preference for less number of children [15]. However, our study results showed that comparatively younger women aged 18 to 27 years were less likely to limit childbearing, which is consistent with low use of any contraceptive methods ever among females of young age category. These findings support other studies which have revealed that family opposition and cultural barrier for contraceptive usage and socio-economic pressure and family preferences for balanced number of children to fulfill family size leads to less desire for limiting childbearing among young females [16, 17]. Other contributing factors such as fear of side effects, lack of knowledge and inadequate outreach services, to overcome barrier for bridging the gap in reproductive services, regarding contraceptive methods lead to low demand for family planning services pushing women to produce more children in their reproductive life $[16,18,19]$.

With respect to the education status of the women, we found that uneducated women were $76 \%$ less likely to have a desire to limit childbearing as compared to their counterparts. This evidence is supported by other studies across the world. For instance, data of 57 demographic health surveys were gathered to determine role of education in determining the fertility of women. These surveys found education as a key predictor of fertility and had a substantial impact on fertility and preference for future family size [20]. An empirical evidence from Colombia showed that demand for more children gets lower among more educated women, hence, effect of schooling is a significant predictor to limit childbearing [21]. Likewise, studies conducted in India, Bangladesh and China also found an inverse linear relationship between education status of the women and their fertility choices [22-24]. The most likely explanation for this evidence is that education enhances increase awareness and thinking capacity of women [20]. Thus, more educated women perhaps better appreciate the health and economic benefits of limiting the family size [20].

Moreover, we found in this study that women having equal number of sons and daughter were more likely to express desire for limiting further childbearing. Our study findings regarding children composition were comparable to studies conducted across other parts of the world. For example, a survey conducted in Kenya showed an evidence regarding sex ratio that women having more number of daughters as compared to the sons had more desire for children as compared to those women who had equal number of son and daughters [8]. A survey conducted among Bangladeshi women found to have stronger son preference which leads to increase desire and reduce the desire to limit childbearing, thus, sex preference is substantial contributor in quantifying fertility desire [25]. Similarly, one of the surveys conducted in Ethiopia found that women having equal sons and daughters had less desire for more children as compared to those having more daughters [13]. Further, these findings could be explained by well-known 'value of children theory' by Hoffman [26, 27]. According to this theory, in developing countries children are considered as an economic asset for the parents thus providing them support in earning mainly in their older age. Therefore, women tend to produce more children with the expectation of giving birth to more sons in order to increase economic certainty of parents $[26,28]$. 
Regarding the socioeconomic status of women, it was found that women of low quintile had a less desire to limit childbearing. It might be due to the fact that children in poor families are considered as a "highbenefit" economic value and couple would thought them as an investment who pay back during their old age as observed in African traditions and culture [13].

With regard to the autonomy of women, our study found that autonomous women were more likely to limit childbearing as opposed to women with limited autonomy. Our study findings are consistent with other studies which indicate that women's 'say' and discussion in family planning have a great impact on fertility preference, thus influencing contraceptive usage as well. For example, one of the studies conducted in Thailand established an inverse relationship between women's autonomy and fertility choice [29]. Likewise, one study conducted in Pakistan showed that autonomy of women was significantly related with ever and current use of contraceptive use which ultimately reflects positive behavior for fertility intentions to have no more children [30].

In addition to the above factors, current contraceptive usage has vital role to play in favorable behavior towards family preference of limiting childbearing as evidenced by study conducted among currently married women in Kenya which found that fertility intentions for no more children was inversely linked with current use of contraceptive [8]. Likewise, study conducted among Nigerian women also revealed that current use of any contraceptive method is a significant predictor for fertility reduction [15]. These evidences support our study findings which found similar relationships between using contraceptive usage and intentions towards limiting childbearing.

The findings from this study should be seen in the light of some limitations. The most significant is that this study did not address fertility preferences of the male partner and childbearing; planning for family size and fertility preference is considered as a negotiable process between both of the partners and should highly depend on mutual agreement between husband and wife. Considering this, male partners should be involved to give holistic insight into couple's attitude towards preference of their future childbearing, practicing reproductive behavior accordingly to the preference and decision to use contraceptive methods. Furthermore, this study would not be generalizable to women residing in rural area as women recruited for this study were from urban residence and rural place of residence have different socio-demographic and reproductive behaviors. This study could not assess temporal association as changes in the preference occur over the period of time due to change in societal, economic and family structure and unavoidable events such as natural disasters or wars and conflicts.

Despite these limitations, this is the first study in Pakistan which have explored the predictors of desire to limit childbearing and could have positive implications if strategize accordingly. In addition to this, the study was conducted as a population based survey which gives an opportunity to report true estimates along with true representation of the population. Additionally, findings from this study can be generalized to other similar urban areas of Pakistan and neighboring countries. Sampling strategy and technique applied to recruit participants was of remarkable value to avoid selection bias. Sample size calculation also used measures from national demographic and health survey thus increasing its robustness. 


\section{Conclusion:}

In summary, the results of our study illustrate that factors such as age, education, wealth quintile, having sons, autonomy and usage of contraceptives were found to be potential predictors of women's desire for limiting childbearing. These factors could be of key importance for creating the demand for reproductive behavior change, for more family planning and the decline in fertility rate among women of reproductive age living in the squatter settlements of Karachi Pakistan. Based on the results of this study, we propose that efforts are required to promote use of family planning among poor young and illiterate women. Moreover, these women can be sensitized through devising behavior change strategies about the fact that more children could be the liability rather than of economic value. Hence, associated predictors found in this study would help to recommend policy measures about enhancing contraceptive use among youth especially through sensitization process and planned interventions to modify their reproductive behavior and fertility intentions.

\section{Abbreviations:}

TFR

Total fertility rate

MWRA

Married women of reproductive age group

AOR

Adjusted odds ratio

$\mathrm{Cl}$

Confidence interval

ACHP

Aman Community Health Program

ATH

Aman Tele Health

\section{Declarations:}

Ethics approval and consent to participate

The study was reviewed and approved by Ethical Review Committee at Aga Khan University (2946-CHSERC-14) PI. Dr. Sarah Saleem. Prior to the interview, the purpose and nature of the study was explained and written informed consent was obtained from each respondent.

Consent for publication: Not applicable

Availability of data and materials

The data of this study is available from the corresponding author on reasonable request. 


\section{Funding}

The present study is based on the baseline data collection of "Sukh Initiative" project funded by Aman Health Care Services of Aman Foundation, Karachi, Pakistan. Funding agency had no role in study design, analyses, interpretation and writing manuscript of the present study. The grant number is "SGA 0614-01"

\section{Competing Interests}

The authors declare that they have no competing interests.

Authors' contributions

SS (Sarah Saleem) conceptualized the main study, wrote the proposal and acquired funding; also supervised the implementation of the study, data analysis and provided mentorship throughout the data analysis and manuscript writing process. SJ (Saleem Jessani) assisted in data management, data analysis and manuscript writing. SR (Shama Razzaq) conceptualized the research question, analyzed the data and wrote the manuscript. SA (Sumera Ali) provided guidance in data analysis and manuscript writing; helped in critically reviewing and improving the final draft of the manuscript. ZA (Zahid Abbasi) assisted in data management and review of the final manuscript. All authors have read and approved the final manuscript for publication.

Acknowledgements

We are thankful to the sponsor, Aman Health Care Services, Program Management Unit and Aman Community Health Program for materializing this endeavor. We would like to express our gratitude to the study participants; without their cooperation, we would not have accomplished our goals.

\section{References:}

1. Ahmed RN, Ahmad K. Impact of Population on Economic Growth: A Case Study of Pakistan. Bulletin of Business Economics (BBE). 2016;5(3):162-76.

2. Population Reference Bureau. World Population Data Sheet, Population Reference Bureau Washington, DC. 2007. Available from: https://www.prb.org/2007worldpopulationdatasheet/. Accessed 05 Nov 2018.

3. Chandra-Mouli V, Svanemyr J, Amin A, Fogstad H, Say L, Girard F, Temmerman M. Twenty years after International Conference on Population and Development: where are we with adolescent sexual and reproductive health and rights? J Adolesc Health. 2015;56(1):S1-S6.

4. Mclntosh CA, Finkle JL. The Cairo conference on population and development: A new paradigm? Popul Dev Rev. 1995;21(2):223 - 60.

5. Trivedi JK, Sareen H, Dhyani M. Rapid urbanization-Its impact on mental health: A South Asian perspective. Indian J Psychiatry. 2008;50(3):161. 
6. Van Bavel J. The world population explosion: causes, backgrounds and projections for the future. Facts Views Vis Obgyn. 2013;5(4):281.

7. National Institute of Population Studies (NIPS)[Pakistan] and Macro International Inc. Pakistan demographic and health survey. 2017-18. Available from https://www.nips.org.pk/. Accessed 14 Dec 2018.

8. Lunani LL. Determinants of fertility preferences among currently married women in Kenya. Population Studies: University of Nairobi; 2014.

9. Mahmood N. The desire for additional children among Pakistani women: the determinants. The Pakistan Development Review. 1992:1-30.

10. Fitaw $Y$, Berhane $Y$, Worku A. Impact of child mortality and fertility preferences on fertility status in rural Ethiopia. East Afr Med J. 2004;81(6):300-6.

11. Najmi H, Ahmed H, Halepota G, Fatima R, Yaqoob A, Latif A, Ahmad W, Khursheed A. Communitybased integrated approach to changing women's family planning behaviour in Pakistan, 2014-2016. Public Health Action. 2018;8(2):85-90.

12. National Institute of Population Studies (NIPS)[Pakistan] and Macro International Inc. Pakistan demographic and health survey. 2012-13. Available from https://www.nips.org.pk/. Accessed 07 Jun 2018.

13. Susuman AS, Bado A, Lailulo YA. Promoting family planning use after childbirth and desire to limit childbearing in Ethiopia. Reprod Health. 2014;11(1):53.

14. Uddin M, Bhuyan K, Islam SS. Determinants of desired family size and children ever born in Bangladesh. J Fam Welf. 2011;57(2):39-47.

15. Adebowale SA, Adeoye IA, Palamuleni ME. Contraceptive use among Nigerian women with no fertility intention: interaction amid potential causative factors. Etude Popul Afr. 2013;27(2):127.

16. Withers $M$, Kano M, Pinatih GNI. Desire for more children, contraceptive use and unmet need for family planning in a remote area of Bali, Indonesia. J Biosoc Sci. 2010;42(4):549-62.

17. Gipson JD, Hindin MJ. 'Marriage means having children and forming your family, so what is the need of discussion?'Communication and negotiation of childbearing preferences among Bangladeshi couples. Cult Health Sex. 2007;9(2):185-98.

18. Islam MM, Bairagi R. Fertility intentions and subsequent fertility behaviour in Matlab: do fertility intentions matter? J Biosoc Sci. 2003;35(4):615-9.

19. Casterline JB, Sinding SW. Unmet need for family planning in developing countries and implications for population policy. Popul Dev Rev. 2000;26(4):691-723.

20. Bongaarts $\mathrm{J}$. Completing the fertility transition in the developing world: The role of educational differences and fertility preferences. Popul Stud (Camb). 2003;57(3):321-35.

21. Forero N, Luis Fernando G. Family Size in Colombia: Guessing or Planning? Intended vs. Actual Family Size in Colombia. Desarro Soc. 2009;3(64):85-118. 
22. Dommaraju P, Agadjanian V. India's North-South divide and theories of fertility change. J Popul Res. 2009;26(3):249.

23. Akmam W. Women's education and fertility rates in developing countries, with special reference to Bangladesh. Eubios J Asian Int Bioeth. 2002;12(4):138-43.

24. Ding QJ, Hesketh T. Family size, fertility preferences, and sex ratio in China in the era of the one child family policy: results from national family planning and reproductive health survey. BMJ. 2006;333(7564):371-3.

25. Mannan MA. Preference for son, desire for additional children and contraceptive use in Bangladesh. Bangladesh Dev Stud. 1988:31-57.

26. Wachira EW. Determinants of fertility preferences in Kenya a study based on the 1998 Kenya demographic and health survey data. Nairobi: University of Nairobi;: PhD Diss; 2001.

27. Holger VL. On the psychological determinants of fertility. A panorama of concepts and approaches, and evidence from eastern Germany. Rostock: Max Planck Institute for Demographic Research; 2006.

28. Campbell EK, Campbell PG. Family size and sex preferences and eventual fertility in Botswana. J Biosoc Sci. 1997;29(2):191-204.

29. Freedman R. Theories of fertility decline: A reappraisal. Soc Forces. 1979;58(1):1-17.

30. Saleem S, Bobak M. Women's autonomy, education and contraception use in Pakistan: a national study. Reprod Health. 2005;2(1):8.

\section{Figures}




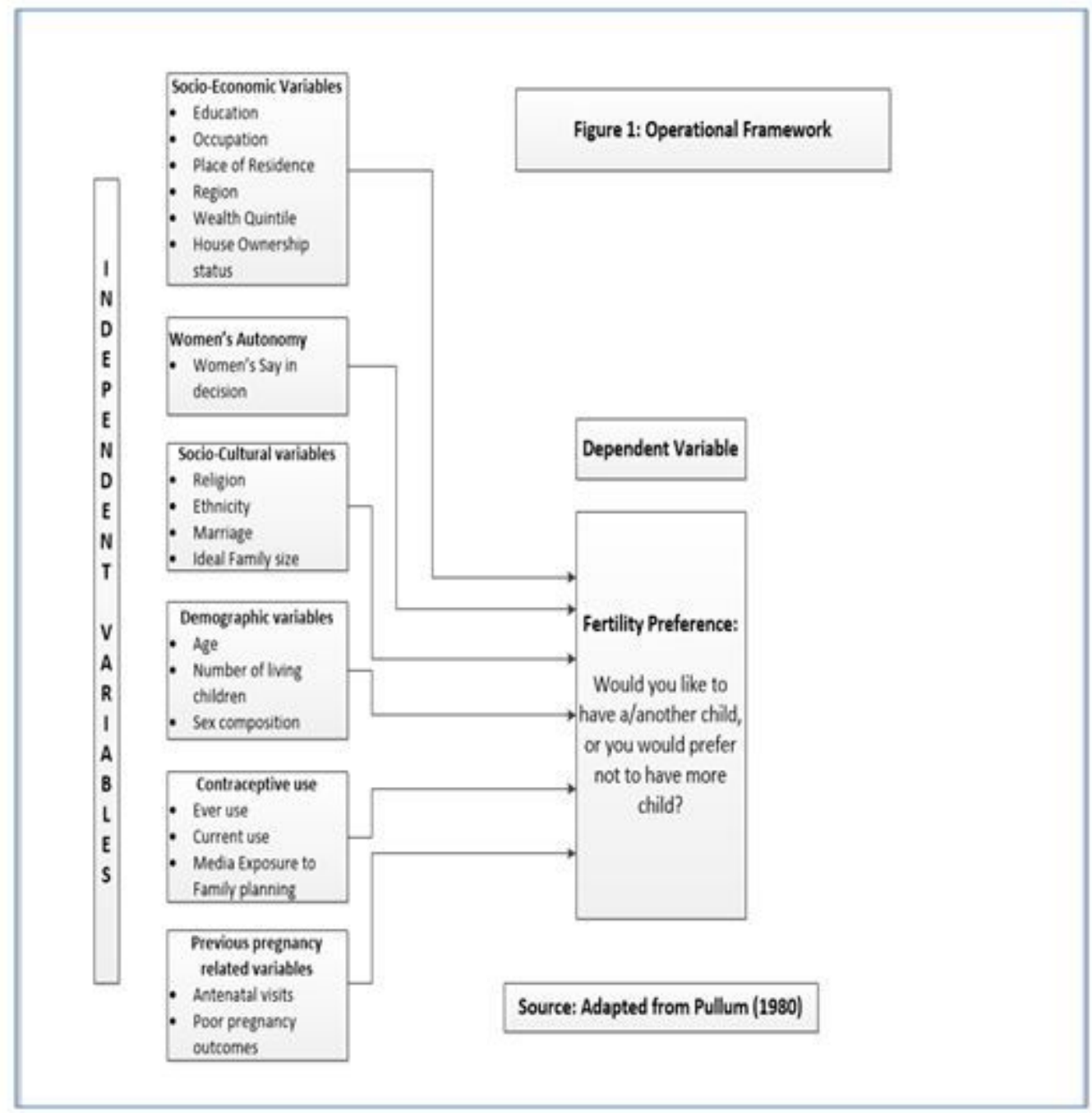

Figure 1

Operational Framework to assess fertility preference

\section{Supplementary Files}

This is a list of supplementary files associated with this preprint. Click to download.

- STROBEChecklist.docx 